\title{
ASSESSING AVALANCHE-RISK LEVELS ON WALKING TRACKS IN FIORDLAND, NEW ZEALAND
}

\author{
by \\ I.F. Owens \\ (Department of Geography, University of Canterbury, Private Bag, Christchurch, New Zealand)
}

and

B.B. Fitzharris

(Department of Geography, University of Otago, P.O. Box 56, Dunedin, New Zealand)

\section{ABSTRACT}

Walking tracks which cross relatively rugged avalancheprone terrain are becoming increasingly popular in New Zealand. Consequently, there exists the need to develop a methodology by which it will be possible objectively to assess the avalanche hazard in the vicinity of the tracks. This paper outlines some procedures that have been used to map avalanche paths, and introduces modifications to an internationally used highway hazard index employed to quantify the danger to walkers. The Fiordland region of south-west New Zealand is an area of spectacular scenic beauty, made famous by the Milford Track which has been walked by large numbers of tourists since the late nineteenth century. In recent years, avalanches have killed one person on the track, severely damaged a lodge, and destroyed several small bridges. Other walking tracks have been opened to tourists in this century and one of these, the Routeburn Track, is included in this study. Avalanche paths which affected the Milford and Routeburn Tracks were mapped in the field using well-established techniques and applying the results of previous research on the Milford Road, where historical records are available for a period of 50 years. The risk to walkers was assessed with a hazard index which depends on frequency of avalanches, numbers of paths, time taken to traverse each path, and numbers of walkers using the track. Results indicate that the avalanche hazard is low to moderate on the Milford Track and moderate on the Routeburn Track. The management implications of these findings are outlined.

\section{INTRODUCTION}

Walking tracks in New Zealand are becoming increasingly popular as alpine environments and active recreation form the basis of a tourist boom. Many of these tracks, and especially those in the Fiordland region, cross relatively rugged avalanche terrain so that there is a need to develop a methodology making it possible objectively to assess the hazard involved. Methods of assessing and mapping avalanche terrain are well known and include the work of Martinelli (1974), and in North America systems have been developed for establishing a hazard index for major roads as a function of number, magnitude, and frequency of avalanche and volume of traffic flows (British Columbia. Ministry of Highways, 1974; Armstrong, 1981). We have already applied these approaches to the only major highway affected by avalanches in New Zealand, the Milford Road (SH '94 to Milford Sound, Fig. 1) (Fitzharris and Owens, 1980). In this paper, however, we are concerned with extending this approach to walking tracks in the Fiordland area.

\section{STUDY AREA}

The Fiordland area is located in the south-west of the South Island of New Zealand. Most of the area is incorporated into Fiordland National Park (FNP), a world heritage park. It is an area of spectacular scenic beauty which derives mainly from the effects of Pleistocene glaciation, and whose features are consequences of the presence particularly in the west of the region of relatively resistant bedrock of granites and gneisses. In the west there are very steep-sided valleys separated by ridges and peaks at elevations of ten in excess of $2000 \mathrm{~m}$. Further east, towards Lake Wakatipu (Fig. 1), sedimentary rocks and schist are more common and the glacial features are consequently less well preserved.

The climate is characterized by high though spatially variable precipitation, relatively warm temperatures compared with other mid-latitude mountain areas, and windiness. In the west of the region, maximum mean annual precipitation approaches $10000 \mathrm{~mm}$ while in the east it falls to about $1000 \mathrm{~mm}$. While snow may occupy valley bottoms in mid-winter for a week or so, periods of snow-lie much longer than this are relatively rare. In most winter and spring storms, the freezing level is at a significant height above valley bottoms. High winds result from the barrier of the Southern Alps, approximately at right-angles to the prevailing westerlies, in the latitude of the roaring forties. This climate produces a relatively deep, dense snow-pack with abundant ice layers (reflecting fluctuating freezing levels) and frequent thick layers of heavily rimed snow (graupel); kinetic growth of snow grains within the pack is probably quite rare. As a consequence of these factors most snow avalanches result from heavy precipitation events, often in conjunction with strong winds, although warming temperatures may also contribute to avalanche initiation especially in spring and summer.

Vegetation is dominated by mountain and silver beech (Nothofagus solandri var. cliffortiodes and $N$. menziesii). In the west, the timber line is at approximately $900 \mathrm{~m}$, and it rises to about $1000 \mathrm{~m}$ in the east.

\section{WALKING TRACK HISTORY, MANAGEMENT, AND USE}

\section{The Milford Track}

New Zealand's most famous walking track, the Milford Track, is a $55 \mathrm{~km}$ trail between the head of Lake Te Anau and Milford Sound in Fiordland National Park (Fig. 1). The northern part of the track, Arthur Valley, was used in the 1880 s by tourists from ships anchored in Milford Sound. In 1888, the explorer Quintin Mackinnon discovered the route by struggling up the Clinton Valley and crossing the $1154 \mathrm{~m}$ 


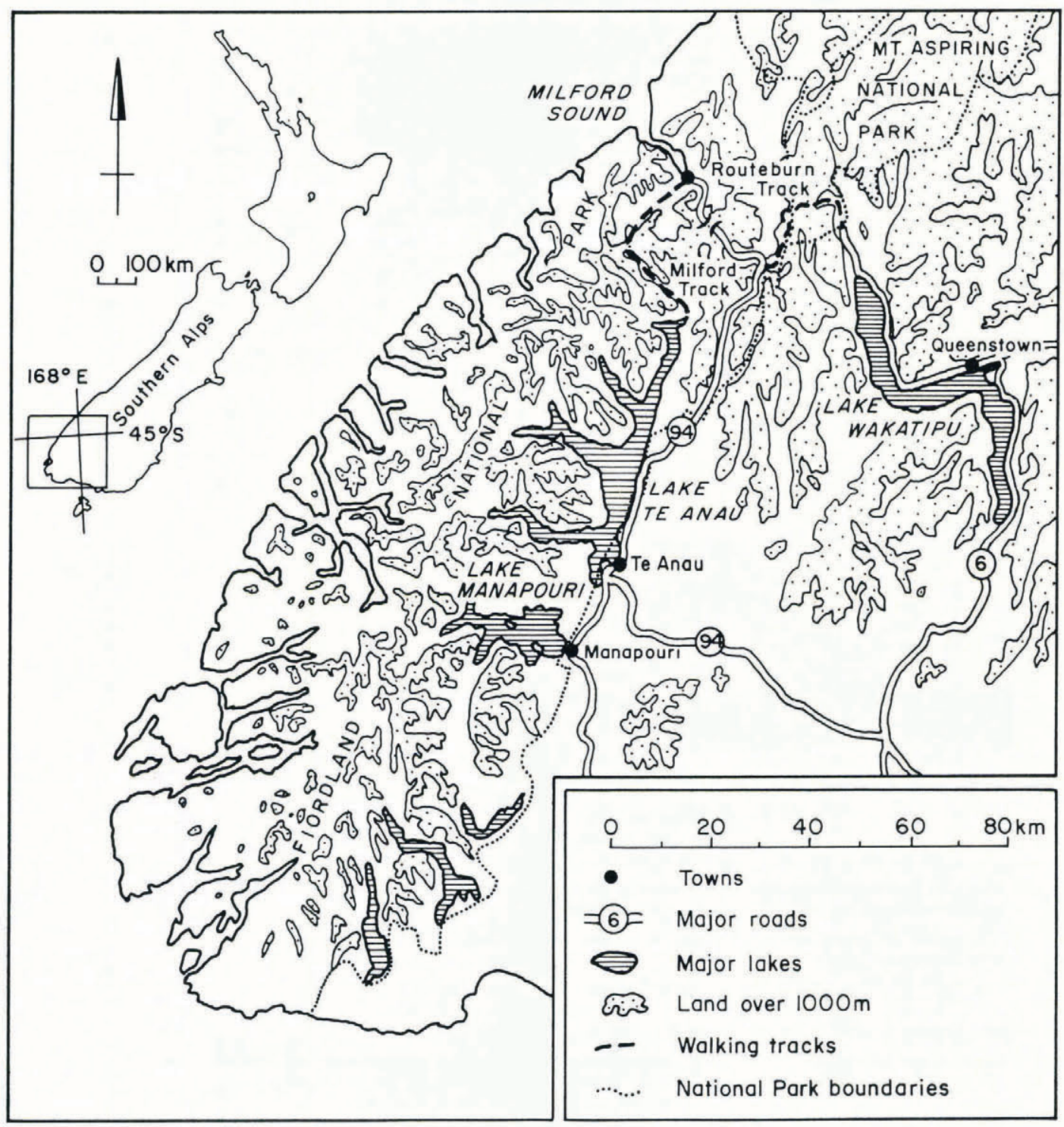

Fig. 1. Location of the Fiordland study area.

pass that bears his name (Fig. 2). By the 1890s, the track was being strongly promoted as a tourist attraction, and amenities were therefore built. In 1908 it was described by The Spectator of London as the "Finest walk in the world". In these early years it is thought that approximately 200 people per year walked the track, and by 1930 numbers had probably risen to about 1000 per year. The Tourist Hotel Corporation (THC) administered access, accommodation and guiding, but in the late 1960 s freedom walkers were first allowed on the track. Compared with THC walkers, they pay relatively small hut fees (for less well-equipped FNP huts) and must carry all food, clothing, and sleeping requirements. In the $1967-68$ season, there were 2681 THC walkers using the track, and by 1983 the total numbers on the track had risen to 7000 , made up of 4000 THC walkers and 3000 freedom walkers.

Access to the beginning of the track at the head of Lake Te Anau is by boat, and walkers move in one direction only, from Lake Te Anau to Milford Sound. Both THC and FNP huts are booked in advance, and walkers are expected to move to the next hut at the beginning of each day unless prevented by weather, flood, or avalanche from advancing further. Generally, the track is in use only from November to March; this avoids the main avalanche period which occurs from May to November with peak activity in August and September. Although right of access is guaranteed by the National Parks Act, it can be controlled by not providing a boat service to the head of Lake Te Anau. However, in spite of this control measure, it is known that a small number of walkers do obtain access across a difficult pass from State Highway 94.
The majority of the track lies below the timber line in the valley bottom, apart from the section at the Mackinnon Pass. This section of the track provides the most spectacular views but also includes the most dangerous avalanche terrain. To the north of the pass the track crosses several large avalanche paths and many small ones, and for this reason a steeper and more direct emergency track, which avoids these areas, is used at times of high avalanche risk (Fig. 2). This section was the scene of the only fatality known to have occurred on the track, when a trainee ranger was buried by an avalanche off Mount Elliott during a storm in November 1982. Avalanches have frequently caused damage to bridges elsewhere on the track, and in September 1983 avalanche activity led to the relocation of the THC huts at Pompolona. In this case a large avalanche blocked the Clinton River and the foundations of the huts were undermined where the dam was breeched.

\section{The Routeburn Track}

The $39 \mathrm{~km}$ Routeburn Track is located partly in Mount Aspiring National Park and partly in Fiordland National Park, and provides a route between the head of Lake Wakatipu and the Divide on State Highway 94 (Fig. 3). Tourist activity began here in the $1880 \mathrm{~s}$, although only at the Wakatipu end of the track. A through route was not established until the 1930s and initially there were far fewer walkers than on the Milford Track. In the 1968-69 season there were only 619 walkers, but by the end of the 1970s this had increased ten-fold (Harris, 1983). By the mid-1980s numbers of walkers using the track had increased to 8000 each year. 


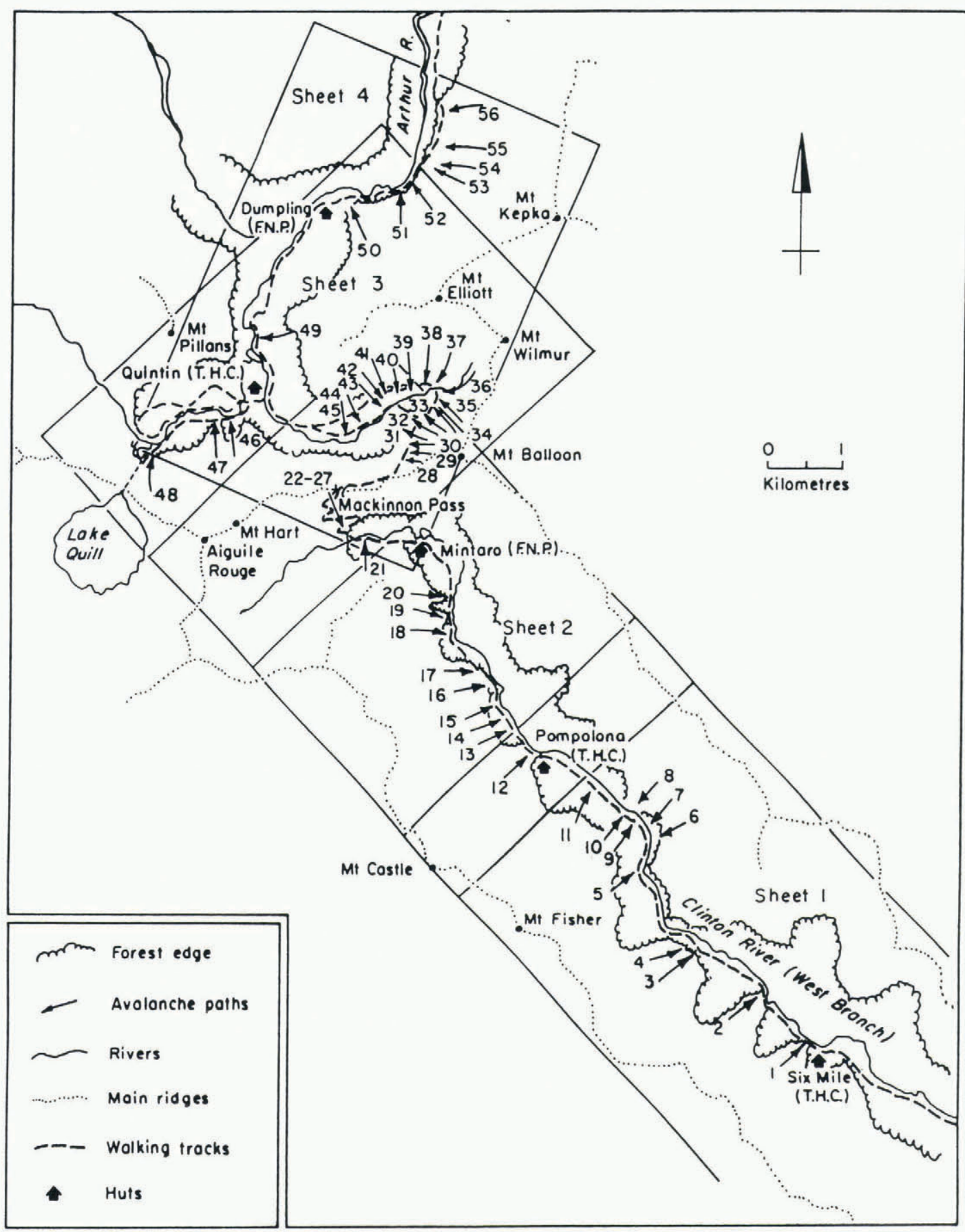

Fig. 2. Avalanche-affected section of the Milford Track showing location of avalanche paths and coverage of the $1: 25000$ sheets.

Compared with the Milford Track, there is much less control on walkers using the Routeburn Track, who may for example travel along it in either direction, and on which hut booking is not necessary. A small number of walkers are guided by a concessionaire and stay in separate huts at Routeburn Falls and Lake Mackenzie. It is thought that in the winter months of June-September about 200 people use the track (personal communication from B. Ahern).

Almost one-third of the Routeburn Track is above timber line, a much greater proportion than of the Milford track. The track first emerges above the beech forest just beyond Routeburn Falls hut and proceeds towards Lake Harris along a relatively flat section of alpine meadows. Just before Lake Harris the track climbs around some bluffs which were the scene of an avalanche accident during a search-and-rescue exercise in September 1984. The Harris Saddle is at an elevation of almost $1300 \mathrm{~m}$, significantly higher than the Mackinnon Pass on the Milford Track. From the Harris Saddle the track proceeds another $5 \mathrm{~km}$ above the timber line, mainly along the exposed eastern side of the Hollyford Valley, before descending to Lake Mackenzie. Apart from some sections of the track where avalanches have removed forest, the remainder of the track to the Divide is below the timber line.

\section{AVALANCHE-TERRAIN MAPPING}

Avalanche paths were mapped in the field using the techniques discussed by such authors as Martinelli (1974). Mapping of starting zones, tracks, and run-out zones was based on:

(a) Observation of vegetation and geomorphic characteristics in the field, and air photographs.

(b) Inspection of oblique photography from fixed wing aircraft and/or helicopter.

(c) Interviews with National Park staff and present and former THC staff. (Some of these personnel accompanied us on our field work.) 


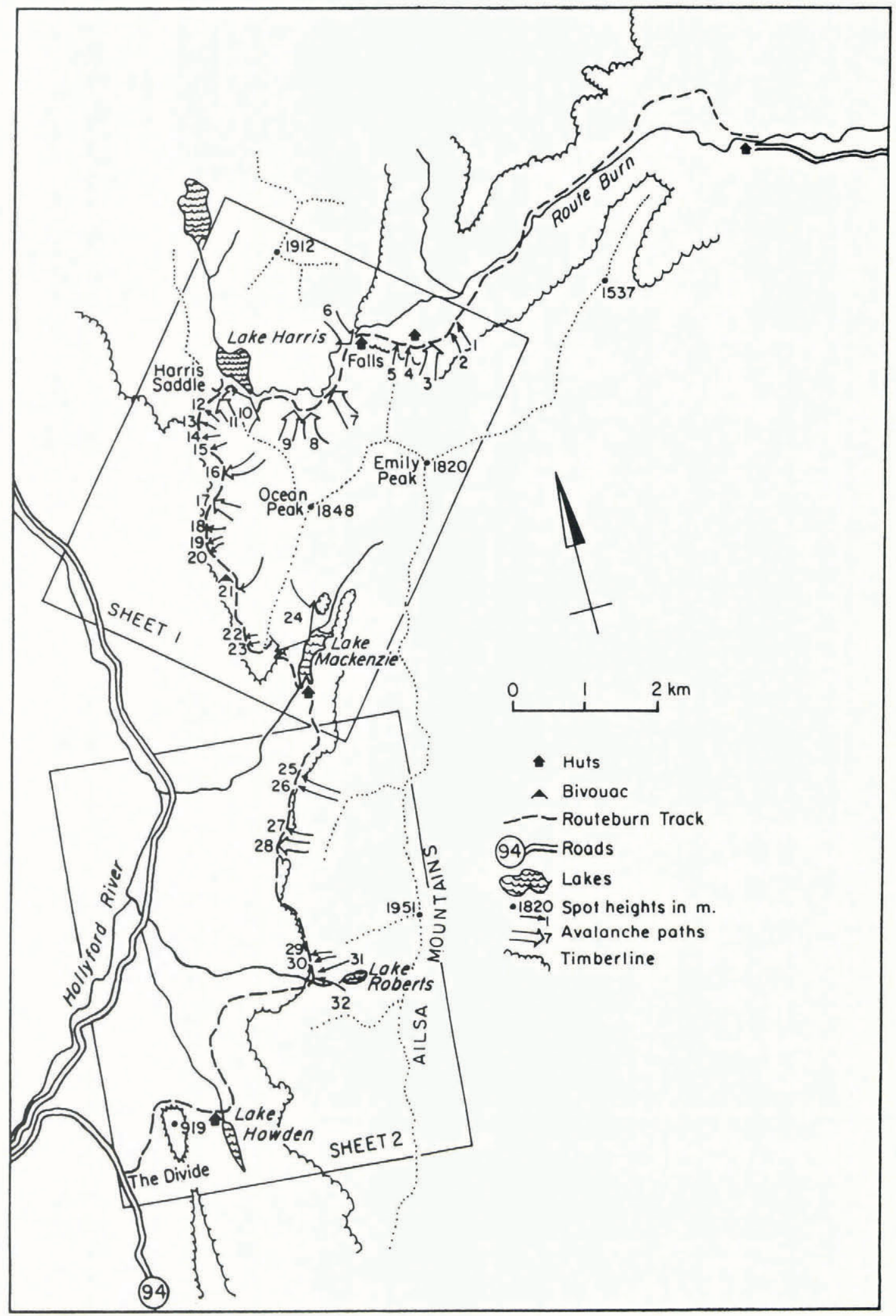

Fig. 3. The Routeburn Track showing avalanche paths and coverage of the $1: 25000$ sheets.

The avalanche paths were plotted on maps at a scale of approximately $1: 15000$ and each path was given a commonly used or local name to assist with subsequent data collection. For each path the frequency of avalanches was estimated from vegetation characteristics such as species and stage of regrowth, other terrain characteristics, documented evidence where available, and by applying our experience gained from work on the Milford Road (Fitzharris and Owens, 1980) where records of avalanche frequency are available back to 1936. Avalanche maps are published at $1: 25000$ along with an oblique photograph for each path to assist in identification (Owens and Fitzharris, 1985).

Fifty-six paths were mapped on the Milford Track and
32 on the Routeburn Track. The average areas of starting zone (Table I) indicate that paths on the Milford Track were generally the larger. The anomalously high track angles reflect the strong glacial imprint on the topography in the Clinton and Arthur Valleys, an effect which is less obvious in the Routeburn area. However, the slope angles of run-out zones are greater on the Routeburn Track, reflecting the fact that smaller avalanches mainly run out on to relatively steep mountain slopes, along the Milford Track whereas a greater proportion of the avalanches run out on to valley bottoms. The greater elevation ranges of the Milford Track avalanche paths are also clearly evident from Table I. 
TABLE I. AVALANCHE-PATH CHARACTERISTICS

Milford Track Routeburn Track

Number of paths

56

32

0.085

Angle $\left({ }^{\circ}\right)$

$850-2070$

$250-1840$

Track

Angle $\left({ }^{\circ}\right)$

Elevation range $(\mathrm{m})$

47

$60-1590$

38

$910-1520$

Run-out

Angle

Elevation range $(\mathrm{m})$

18

$50-1040$

25

$810-1340$

\section{AVALANCHE HAZARD-INDEX CALCULATIONS}

The hazard index was originally developed overseas for studies of avalanches on highways (British Columbia. Ministry of Highways, 1974) and has also been applied to highways in New Zealand (Fitzharris and Owens, 1980; Fitzharris and others, 1984). This method has been modified to allow the calculations of potential hazard to walkers. The hazard is a function of:

(a) Magnitude of avalanche.

(b) Frequency of avalanche occurrence.

(c) Number of avalanche paths.

(d) Time a walker takes to cross each avalanche path.

(e) Numbers of walkers who use the track.

For each avalanche path, the avalanche index is calculated as follows:

$$
P_{x}=\frac{t_{\mathrm{e}}}{t_{x}} f_{\mathrm{x}} W
$$

where $P_{X}$ is the product of severity and probability of an avalanche encounter/person; $t_{\mathrm{e}}$ is the time for which a walker is exposed to hazard; $t_{x}$ is the length of period during the year considered; $f_{x}$ is the frequency of avalanching in period $x ; W$ is the weighting factor to indicate severity of avalanche encounter.

For highway studies in Canada, values of $W=1,4$, and 10, corresponding to powder snow, light snow, and deep snow were used. In this study it is assumed that $W=10$ is appropriate for walkers because quite small avalanches may cause death or serious injury.

The hazard index is then given by:

$$
I_{x}=N_{x} \Sigma P_{x}
$$

where $N_{x}$ is the number of walkers in period $x$ each year and $\Sigma$ is the sum of all avalanche paths along the walking track.

Because of the different patterns of use and different avalanche seasonality, varying periods were used for calculating the hazard index, as shown in Table II. Because of the great elevation of starting zones and the fact that a significant proportion of them is on permanent ice fields, avalanches can potentially occur at any time of year on the Milford Track. Consequently, calculations were made for the walking season and for the winter. On the Routeburn Track, avalanche occurrence is restricted to a short winter period, June-September, and a 3 month spring period from October to December.

The results of the hazard-index calculations are shown
Season

Winter

TABLE II. TRACK SEASONS AND NUMBER OF WALKERS $(N)$ USED IN HAZARD-INDEX CALCULATIONS

$\begin{array}{llc}\text { Season } & \text { Milford Track } & \text { Routeburn Track } \\ \text { Winter } & \text { April-October } & \text { June-September } \\ & (7 \text { months }) & (4 \text { months }) \\ & N_{\mathrm{w}}=150 & N_{\mathrm{w}}=200\end{array}$

Spring

October-December

(3 months)

$N_{\mathrm{S}}=3000$

Walking season November-March

(5 months)

$N_{\mathrm{S}}=7000$

in Table III. These indicate that, despite the more dangerous avalanche terrain on the Milford Track the indices calculated for the Routeburn Track are larger. This is mainly a result of heavy use of the track in the spring months, October-December. However, it also partly results from the fact that the Routeburn Track, in its middle section, of ten crosses relatively wide and steep parts of avalanche paths so that walkers are exposed to danger for longer periods of time. The avalanche paths where the track crosses the bluffs near Lake Harris and the zig-zags above Lake Mackenzie exemplify this in particular. In contrast, most of the Milford Track avalanche paths, although they are greater in number and appear more menacing, are crossed in the valley bottom where they are of ten narrow and can be traversed more quickly.

TABLE III. RESULTS OF HAZARD-INDEX CALCULATIONS

Milford Track Routeburn Track

Winter

$6.0(4.4)^{*}$

Spring

Walking season

$8.3(7.7)$

Total

Following the practice of overseas studies, the hazardindex values can be classified as shown in Table IV. In Table V the hazard-index values are compared with those for other tracks and highways in New Zealand and overseas. This comparison indicates that the hazard index of the Routeburn Track is greater than for any other walking track so far studied in New Zealand, and is similar to the index for the Milford Road. However, traffic-volume increases since 1979 when the Milford Road index was

\section{TABLE IV. CLASSIFICATION OF HAZARD-INDEX VALUES}

$\begin{array}{lcl}\text { Rating } & \text { Hazard index } & \text { Appropriate response } \\ \text { Very low } & <1 & \text { None } \\ \text { Low } & 1-10 & \begin{array}{l}\text { Warning signs, occa- } \\ \text { sional closure }\end{array} \\ \text { Moderate } & 10-100 & \begin{array}{c}\text { Closure, limited } \\ \text { control }\end{array}\end{array}$

Full control programme 
TABLE $V$, COMPARISON OF HAZARD-INDEX VALUES WITH THOSE FROM PREVIOUS HIGHWAY AND WALKING TRACK STUDIES

Area

$\begin{array}{cc}\begin{array}{c}\text { Average daily } \\ \text { traffic }\end{array} & \text { Hazard } \\ \text { Index }\end{array}$

High hazard

Rogers Pass, Canada

900

Fraser Canyon

Highway 550, U.S.A.

3000

335

140

126

Moderate hazard

Pine Pass, Canada

Routeburn Track

Milford Road, N.Z.

Bear Pass, Canada

Bridge River, Canada

675

Index

Milford Track

400
3502
80
30
30
5001

53

47

46

37

14

12

\section{Low hazard}

Ball Hut Road, N.Z

Bella Coola, Canada

Manganui Gorge Track,

Mount Egmont, N.Z.

Nelson Lakes National

Park tracks

$\begin{array}{rr}40 & 9 \\ 12 & 5 \\ 160 & 2 \\ 2 & 1\end{array}$

Very low hazard

Laidlaw, Canada

Ningunsaw Pass, Canada

4400

15

0.2

Sources: British Columbia. Ministry of Highways (1974), Armstrong (1981), Fitzharris and Owens (1980), Fitzharris and others (1984), Wyles (unpublished), and Owens and Fitzharris (1985).

calculated have probably increased the index there to close to 100 (personal communication from A. Dennis).

\section{APPLICATIONS TO MANAGEMENT}

The most appropriate responses for different levels of the hazard-index are shown in Table IV. Moderate hazard rating indicates that signs should be posted to warn walkers of the most dangerous areas and also to indicate the safe stopping areas. Closure may be necessary at times of high avalanche likelihood, and some limited control may be needed.

Hazard-index calculations for individual avalanche paths allow the identification of areas of the track where the greatest risk occurs. This information is also valuable for deciding on locations for emergency shelters, rescue caches, and track relocation. However, the potential for track relocation is quite limited. Because of greater control of access and availability of meteorological information, the potential for successfully applying track closure in periods of high instability is greater on the Milford Track. A high-elevation meteorological station is sited above the Milford Road and can be interrogated by an avalanche forecaster based at $\mathrm{Te}$ Anau who also periodically evaluates snow-pack stability in the starting zones above the Milford Road. Decisions on closure are most appropriately made by
National Park staff based at Mintaro Hut just before the ascent to the Mackinnon Pass. For the Routeburn Track, there is no high-elevation meteorological information and little restriction on access, so that control in times of high avalanche risk may be limited to strong warnings regarding the dangers involved. This difficulty is compounded on the Routeburn Track by its relatively high elevation, which means that the threat of exposure is very real.

The method of calculating the hazard index for tracks allows for simple recalculation without further field work if the numbers of walkers increase or if the length of walking season is changed. For walking tracks, the hazard index is a linear function of the numbers of walkers, whereas for highways the function is non-linear. This arises from the fact that track-walkers are able to cross avalanche deposits, whereas road traffic stopped by an avalanche may be hit by an avalanche in an adjacent path.

\section{CONCLUSIONS}

This study has shown that procedures for mapping avalanche terrain, and for assessing the level of hazard on mountain highways, can satisfactorily be adapted for assessing the hazard on walking tracks. It has also shown that the physical severity of avalanching is only one component of the hazard, timing and volume of track use and the location of walking tracks in avalanche zones being equally important.

Application of the methods outlined here allows appropriate management options to be determined. In addition, the effect of increased numbers of walkers and any changed timing of path usage can easily be incorporated into recalculations of the hazard index.

\section{ACKNOWLEDGEMENTS}

The research was funded by the New Zealand Mountain Safety Council. Special thanks are due to present and former staff of the Tourist Hotel Corporation and Fiordland and Mount Aspiring National Parks who provided both hospitality and large experience of the Fiordland area. Thanks are also due to $\mathrm{T}$. Shatford and A. Dyer who drew the diagram.

\section{REFERENCES}

Armstrong, B.R. 1981. A quantitative analysis of avalanche hazard on U.S. Highway 550, southwestern Colorado. Proc. West. Snow. Conf., 49, 95-104.

British Columbia. Ministry of Highways. 1974. Avalanche Task Force report. Victoria, British Columbia, Ministry of Highways.

Fitzharris, B.B. and I.F. Owens. 1980. Avalanche atlas of the Milford Highway and assessment of the hazard to traffic. Wellington, N.Z. Mountain Safety Council. (Avalanche Committee Report 4.)

Fitzharris, B.B., D.I. Campbell, G.M. Smith, P.R. Blucher, and C.W. Ho. 1984. Avalanche atlas of the Ball Hut Road and assessment of the hazard to traffic. Wellington, N.Z. Mountain Safety Council. (Avalanche Committee Report 6.)

Harris, C.M. Unpublished. Recreation on the Routeburn Track: image and experience. (B.A. (Hons) dissertation, University of Otago, 1983.)

Martinelli, M., jr. 1974. Snow avalanche sites; their identification and evaluation. U.S. Dep. Agric. Agric. Inf. Bull. 360.

Owens, I.F. and B.B. Fitzharris. 1985. Avalanche atlas of the Milford Track and assessment of hazard to walkers. Wellington, N.Z. Mountain Safety Council. (Avalanche Committee Report 8.)

Wyles, J.M. Unpublished. The identification of snow avalanche paths in Nelson Lakes National Park. (M.Sc. thesis, University of Canterbury, 1984.) 